\title{
Article
}

\section{Asymmetric photocatalysis over robust covalent organic frameworks with tetrahydroquinoline linkage}

\author{
Chunzhi Li a,b, Yinhua Ma b,c, Haoran Liua ${ }^{a}$, Lin Tao a,b, Yiqi Ren a,b, Xuelian Chena, He Li a,*, \\ Qihua Yang a,\# \\ Dedicated to Prof. Can Li on the occasion of his 60th birthday. \\ a State Key Laboratory of Catalysis, iChEM, Dalian Institute of Chemical Physics, Chinese Academy of Sciences, Dalian 116023, Liaoning, China \\ b University of Chinese Academy of Sciences, Beijing 100049, China \\ c State Key Laboratory of Molecular Reaction Dynamics, Dalian Institute of Chemical Physics, Chinese Academy of Sciences, Dalian 116023, Liaoning, China
}

\section{A R T I C L E I N F O}

\section{Article history:}

Received 27 November 2019

Accepted 23 December 2019

Published 5 August 2020

\section{Keywords:}

Photocatalysis

Covalent organic frameworks

Tetrahydroquinoline linkage

Asymmetric catalysis

Ultrastability

\begin{abstract}
A B S T R A C T
The asymmetric photocatalytic organic synthesis (APOS) process is a sustainable and environmentally benign method for the production of optically active chemicals with sunlight as an energy source. However, it still lacks efficient semiconductors with tunable band structures and has a low recycling stability. Herein, we report the synthesis of tetrahydroquinoline-linked covalent organic frameworks (QH-COFs) with irreversible tetrahydroquinoline linkage as efficient semiconductors for the visible-light-driven asymmetric $\alpha$-alkylation of aldehydes by merging with a chiral secondary amine. Up to $94 \%$ ee was obtained over QH-COFs, and the activity of QH-COFs was significantly higher than those of inorganic semiconductors (e.g., $\mathrm{TiO}_{2}, \mathrm{BiVO}_{4}$, and $\mathrm{WO}_{3}$ ) under similar conditions, which is mainly attributed to their narrow band gap and suitable band edge. As far as we know, QH-COFs are the most active semiconductors for asymmetric $\alpha$-alkylation of aldehydes ever reported. The QH-COFs were prepared via a one-pot Povarov cascade imine formation and cycloaddition reaction using $\mathrm{Sc}(\mathrm{OTf})_{3} / \mathrm{Yb}(\mathrm{OTf})_{3}$ as Lewis acid catalysts. Attributed to the tetrahydroquinoline linkage, QH-COFs showed extremely high recycling stability, which made practicals application possible. This work not only opens up a new avenue for asymmetric photocatalysis but also provides an efficient and general method for the construction of robust COFs.
\end{abstract}

(C) 2020, Dalian Institute of Chemical Physics, Chinese Academy of Sciences. Published by Elsevier B.V. All rights reserved.

\section{Introduction}

The asymmetric photocatalytic organic synthesis (APOS) process is a sustainable and environmentally benign method for the production of optically active chemicals with sunlight as an energy source [1-3]. Most APOS processes employ a dual catalysis approach consisting of organic dyes/inorganic semiconductors and chiral catalysts for light absorption and chiral induction, respectively. In general, organic dyes confront problems with narrow absorption bands and low photostability, while the band gap and band edge of inorganic semiconductors are difficult to be tuned $[4,5]$. Furthermore, the efficiency of

\footnotetext{
* Corresponding author. Tel: +86-411-82463019; Fax: +86-411-84694447; E-mail: lihe@dicp.ac.cn

\# Corresponding author. Tel: +86-411-84379552; Fax: +86-411-84694447; E-mail: yangqh@dicp.ac.cn

This work was supported by the National Natural Science Foundation of China (21733009, 21621063), and the Strategic Priority Research Program of Chinese Academy of Sciences (XDB17020200).

DOI: 10.1016/S1872-2067(20)63572-0 | http://www.sciencedirect.com/science/journal/18722067 | Chin. J. Catal., Vol. 41, No. 8, August 2020
} 
APOS is strongly related to the textural structure and surface properties of the semiconductors, because the interphases of the semiconductors with the asymmetric catalysts and the reactants play an important role in achieving efficient electron transfer and chiral induction [6,7]. Therefore, the development of semiconductors with designable band structures, textural structures, and surface properties is of extreme importance for APOS.

Covalent organic frameworks (COFs) [7-14] with periodically ordered structures, high surface areas, and tunable band gaps and band edges are potential organic semiconductors in the field of photocatalysis and have been successfully used for photocatalytic $\mathrm{H}_{2}$ production [7,15-21], $\mathrm{CO}_{2}$ reduction [22-25], and organic synthesis [26-32]. The COFs with reversible $\mathrm{C}=\mathrm{N}$ or B-O-B as a linkage are not stable enough in acid/base medium and under light irradiation, which is one of the biggest obstacles to their applications. Intensive efforts have been devoted to improving the stability of COFs by replacing the reversible chemical bond with an irreversible bond [29,32-42]. For example, the direct cascade transformation of the imine linkage of COFs with phenolic hydroxyl to oxazole linkage [32] and the post-synthesis conversion of imine-linked COFs to amide-linked and quinoline-linked COFs have been reported $[33,34]$. Recently, Yaghi's groups successfully constructed highly stable dioxin-linked and olefin-linked COFs via an irreversible nucleophilic aromatic substitution reaction and Knoevenagel condensation reaction, respectively $[35,36]$.

However, the reported stable COFs synthesized via the one-pot approach are only limited to some special monomers [32,36-38]. This not only makes the monomer synthesis tedious but also limits the universality of the synthesis method. It is highly desirable to use independent transformation reagents instead of attaching them to the monomers. Through a literature survey, we found that tetrahydroquinoline derivatives could be formed by cascade condensation and cycloaddition reactions of amine, aldehyde, and alkene (Povarov cascade reaction, Scheme 1) with Lewis acids as catalysts, such as $\mathrm{Yb}(\mathrm{OTf})_{3}$ and Sc(OTf) 3 [43-45]. More importantly, the Povarov cascade reaction has a wide substrate scope. Previous reports also demonstrated the efficiency of $\mathrm{M}(\mathrm{OTf})_{3}(\mathrm{M}=\mathrm{Sc}, \mathrm{Eu}, \mathrm{In}, \mathrm{Yb}$, $\mathrm{Y}$, etc.) for the formation of COFs with imine linkage [46]. Therefore, the cascade condensation and cycloaddition reactions may provide a general method for the synthesis of ultrastable COFs with irreversible linkages via the judicious selection of the Lewis acids.

Herein, we report an efficient and general method for the synthesis of ultrastable tetrahydroquinoline-linked COFs (QH-COFs) via cascade condensation and cycloaddition reactions with $\mathrm{Sc}(\mathrm{OTf})_{3} / \mathrm{Yb}(\mathrm{OTf})_{3}$ as the catalysts. As far as we know, this is the first example of the one-pot synthesis of COFs via cascade reactions using aldehydes and amines in the presence of transformation reagents. The successful formation of a tetrahydroquinoline linkage was confirmed by FT-IR and ${ }^{15} \mathrm{~N}$ NMR spectroscopies of the QH-COFs. The QH-COFs exhibited extremely high stability under the acidic/basic conditions and light irradiation. More interestingly, the QH-COFs with visible-light absorption expanding to more than $560 \mathrm{~nm}$ could efficiently catalyze the visible-light-driven asymmetric alkylation of aldehydes in combination with a chiral secondary amine to afford both high yield and high ee for a large substrate scope.

\section{Experimental}

\subsection{Synthesis of QH-COF-1}

A $10 \mathrm{~mL}$ high-pressure flask was charged with 1,3,5-tris(p-formylphenyl)benzene (32.5 $\mathrm{mg}, 0.083 \mathrm{mmol}$ ), benzidine ( $23.0 \mathrm{mg}, 0.125 \mathrm{mmol}$ ), ethyl vinyl ether $(72 \mathrm{mg}, 1$ mmol). A mixture of 1,2-dichlorobenzene and $n$-butyl alcohol $(4: 1 \mathrm{v} / \mathrm{v}, 2.5 \mathrm{~mL})$ was added, and the resulting suspension was sonicated at room temperature until the monomers were fully dispersed. Sc(OTf) 3 (2.5 mg, $0.005 \mathrm{mmol})$ and $\mathrm{Yb}(\mathrm{OTf})_{3}(8.0 \mathrm{mg}$,

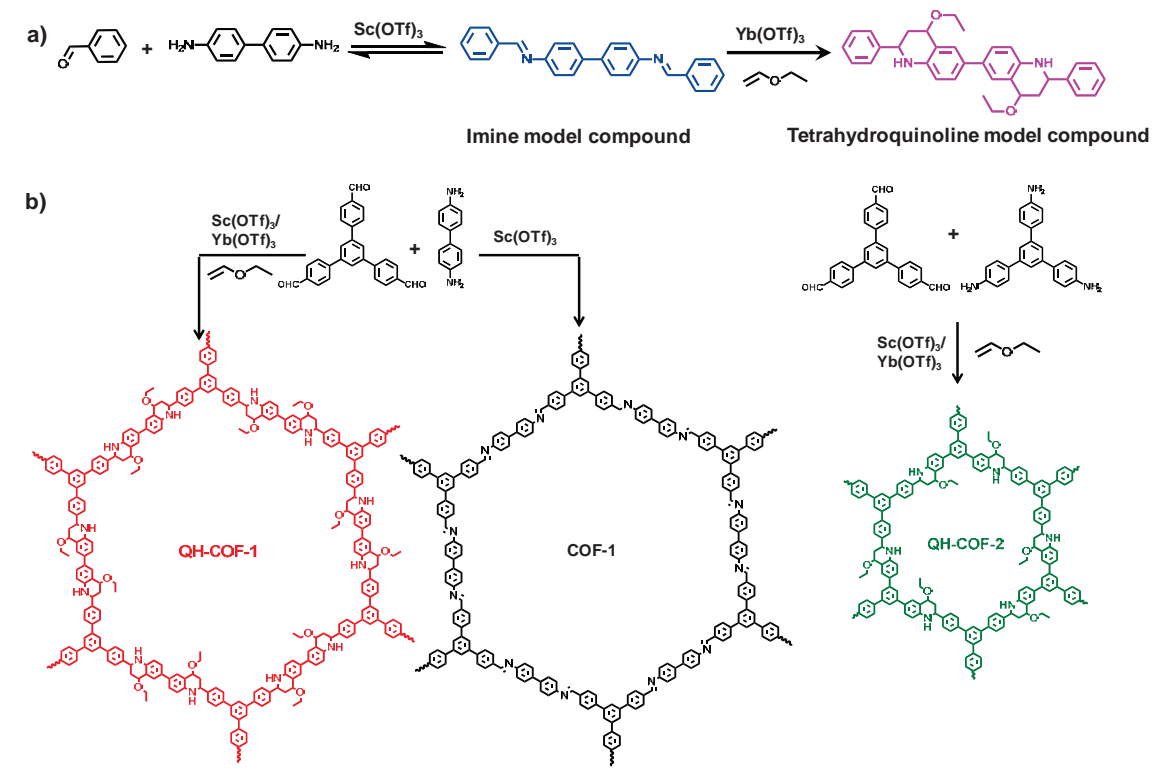

Scheme 1. (a) The construction of imine and tetrahydroquinoline model compounds. (b) Schematic of the construction of QH-COF-1 and QH-COF-2 with tetrahydroquinoline linkage via Povarov cascade reaction and COF-1 with imine linkage. 
$0.013 \mathrm{mmol}$ ) were added, and the resulting suspension was further sonicated for $30 \mathrm{~s}$. The flask was left standing for another $1 \mathrm{~h}$ at room temperature, after which it was degassed through three freeze-pump-thaw cycles. The flask was charged with $\mathrm{N}_{2}$ and sealed under positive $\mathrm{N}_{2}$ pressure; thereafter, it was placed without stirring in a $120^{\circ} \mathrm{C}$ pre-heated oil bath for three days. The solid product obtained after filtration was washed with methanol several times and extracted by Soxhlet extraction using methanol for 1 day, followed by a supercritical $\mathrm{CO}_{2}$ drying process to obtain a brown solid, which was denoted as QH-COF-1.

\subsection{Synthesis of QH-COF-2}

QH-COF-2 was synthesized in a similar way to QH-COF-1 with 1,3,5-tris(p-formylphenyl)benzene and 1,3,5-tris(4-aminophenyl)benzene as monomers in the presence of ethyl vinyl ether.

\subsection{General procedures of the asymmetric photocatalysis}

An oven-dried $15 \mathrm{~mL}$ flat-bottomed flask equipped with a piece of quartz glass and magnetic stir bar was charged with a semiconductor $(30 \mathrm{mg})$, the corresponding bromide $(0.809$ mmol, 1.0 equiv.), and (2R,5S)-2-tert-butyl-3,5-dimethylimidazolidin-4-one triflate $(0.162 \mathrm{mmol}, 0.2$ equiv.). The flask was charged with $\mathrm{N}_{2}$, and $2.0 \mathrm{~mL}$ of dry DMF was added using a syringe, followed by the corresponding aldehyde $(1.62 \mathrm{mmol}$, 2.0 equiv.) and 2,6-lutidine ( $1.62 \mathrm{mmol}, 2.0$ equiv.). The flask was sealed with parafilm and placed approximately $10 \mathrm{~cm}$ from a $30 \mathrm{~W}$ blue light LED (460-470 nm). After the reaction was complete (TLC analysis), the mixture was poured into a separatory funnel containing $5 \mathrm{~mL}$ of ethyl acetate and $5 \mathrm{~mL}$ of $\mathrm{H}_{2} \mathrm{O}$. The layers were separated and the aqueous layer was extracted with ethyl acetate $(3 \times 5 \mathrm{~mL})$. The combined organic layers were dried with $\mathrm{Na}_{2} \mathrm{SO}_{4}$ and concentrated in vacuo. The crude product was purified by column chromatography. The enantiomeric excess was determined by ${ }^{1} \mathrm{H}$ NMR analysis of the corresponding diastereomeric acetals obtained by derivatization with $(2 S, 4 S)$-2,4-pentanediol (for details, see supplementary methods in SI).

\section{Results and discussion}

\subsection{Synthesis and characterizations}

Firstly, benzaldehyde and benzidine were used as model substrates to explore the feasibility of the Povarov reaction for the formation of the tetrahydroquinoline model compound (Scheme 1a). The imine model compound could be facilely obtained by the reaction of benzaldehyde and benzidine in the presence of 0.02 equiv. $\mathrm{Sc}(\mathrm{OTf})_{3}$ under ambient conditions. Next, the imine model compound was reacted with ethyl vinyl ether (EVE) in the presence of $\mathrm{Yb}(\mathrm{OTf})_{3}$ under $\mathrm{N}_{2}$ to afford the tetrahydroquinoline (THQ) model compound.

Inspired by the successful formation of THQ model compound, we attempted to synthesize a tetrahydroquino- line-linked COF (QH-COF-1) via a one-pot reaction of 1,3,5-tris(p-formylphenyl)benzene with benzidine in the presence of EVE (Scheme 1b). Initially, the synthesis conditions for QH-COF-1 were screened, and the results of powder X-ray diffraction (PXRD) studies show that the QH-COF-1 with the best crystallinity was obtained when a mixture of $\mathrm{Sc}(\mathrm{OTf})_{3}$ and $\mathrm{Yb}(\mathrm{OTf})_{3}$ was used as the catalyst in $o$-dichlorobenzene/ $n$-butanol $(4 / 1, \mathrm{v} / \mathrm{v})$ at $120{ }^{\circ} \mathrm{C}$ under $\mathrm{N}_{2}$ atmosphere (Fig. S1). A control sample, COF-1, with an imine-linked framework was also synthesized with 1,3,5-tris(p-formylphenyl)benzene and benzidine as monomers using $\mathrm{Sc}(\mathrm{OTf})_{3}$ as the catalyst in the absence of EVE.

The chemical composition of QH-COF-1 was characterized by FT-IR, ${ }^{13} \mathrm{C}$ NMR, and ${ }^{15} \mathrm{~N}$ NMR spectroscopies, and the results were compared with those of COF-1 and model compounds (Figs. 1a-c). In the FT-IR spectrum of COF-1, the characteristic vibration of $\mathrm{C}=\mathrm{N}$ at $1622 \mathrm{~cm}^{-1}$ matched well with the vibration of $\mathrm{C}=\mathrm{N}$ in the imine model compound at $1621 \mathrm{~cm}^{-1}$, suggesting the formation of an imine linkage for COF-1 [47]. QH-COF-1 displays a FT-IR spectrum quite different from that of COF-1. The characteristic vibration of $\mathrm{C}=\mathrm{N}$ disappeared completely accompanied by the appearance of a new peak at $3410 \mathrm{~cm}^{-1}$ assigned to the secondary $\mathrm{N}-\mathrm{H}$ vibration, and the peaks in the range of 2962-2870 $\mathrm{cm}^{-1}$ were attributed to the $\mathrm{C}-\mathrm{H}$ vibrations of the ethylene group. The FT-IR spectrum of QH-COF-1 is almost identical to that of the THQ model compound with a slight red-shift of $\mathrm{N}-\mathrm{H}$ vibration ( 3410 versus $3340 \mathrm{~cm}^{-1}$ ), possibly due to the formation of intramolecular hydrogen bonds among THQ model compounds. The FT-IR results suggest the successful formation of tetrahydroquinoline linkage in $\mathrm{QH}-\mathrm{COF}-1$ via the one-pot Povarov cascade reactions.

In the ${ }^{13} \mathrm{C}$ CP-MAS NMR spectrum of $\mathrm{QH}-\mathrm{COF}-1$, the signals at $13-70 \mathrm{ppm}$ are derived from the carbons of alkyl and alkoxy groups formed via the cycloaddition reaction of imine and EVE, referenced with the corresponding THQ model compound. The aromatic carbons appeared in the range of 149-115 ppm. The weak signal at $156 \mathrm{ppm}$ could be assigned to the carbon of the quinoline ring possibly formed by the oxidation during the Soxhlet extraction process (confirmed by ${ }^{15} \mathrm{~N}$ NMR studies, discussed later). No signals in the range of 13-70 ppm could be observed in the ${ }^{13} \mathrm{C}$ CP-MAS NMR spectrum of COF-1. With the ${ }^{13} \mathrm{C}$ NMR spectrum of the corresponding imine model compound as a reference, the signals at $158 \mathrm{ppm}$ and in the range of 150-116 ppm in the ${ }^{13} \mathrm{C}$ CP-MAS NMR spectrum of COF- 1 could be assigned, respectively, to $\mathrm{C}=\mathrm{N}$ and aromatic carbons (Fig. S2) [48].

To further confirm the formation of the tetrahydroquinoline linkage in QH-COF-1, ${ }^{15} \mathrm{~N}$ labeled QH-COF-1 and COF-1 were synthesized using ${ }^{15} \mathrm{~N}$ enriched benzidine as a monomer (for details, see SI). The signal at $75 \mathrm{ppm}$ assigned to the secondary amine in the ${ }^{15} \mathrm{~N}$ CP-MAS NMR spectrum of $15 \mathrm{~N}$ enriched QH-COF-1 clearly confirmed the formation of a tetrahydroquinoline linkage, which is consistent with the liquid ${ }^{15} \mathrm{~N} \mathrm{NMR}$ spectrum of the ${ }^{15} \mathrm{~N}$ enriched THQ model compound. The weak signal at $311 \mathrm{ppm}$ could be assigned to the nitrogen of quinoline, as discussed above [49]. Only the signal indicative of $\mathrm{C}=\mathrm{N}$ at $325 \mathrm{ppm}$ together with a weak signal at $54 \mathrm{ppm}$ assigned to 

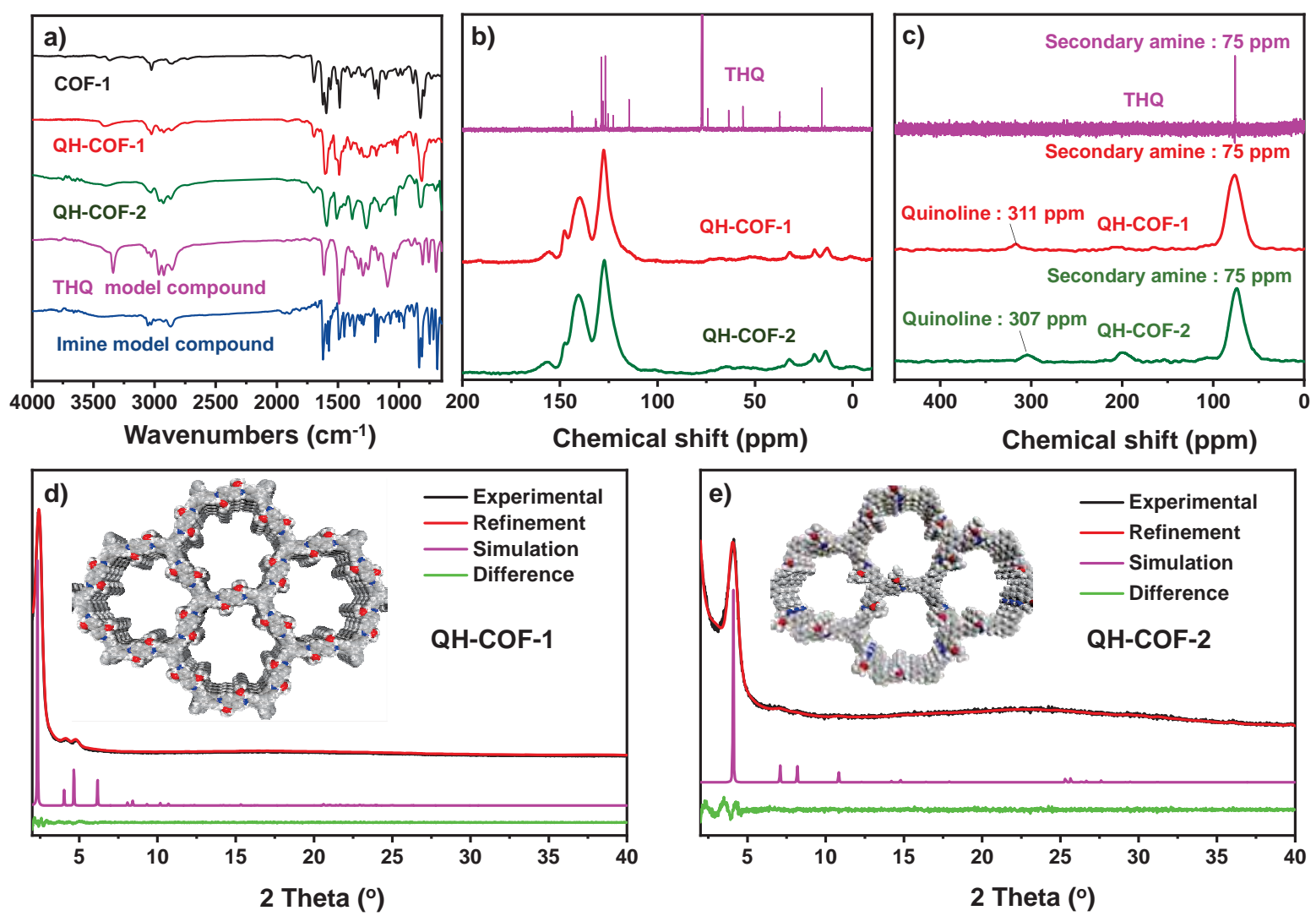

Fig. 1. (a) FT-IR spectra, (b) ${ }^{13} \mathrm{C}$ NMR spectra, and (c) ${ }^{15} \mathrm{~N}$ NMR spectra of the model compounds and COFs. (d, e) Experimental PXRD patterns (black), Pawley-refined (red), and predicted eclipsed structure (magenta) of QH-COFs (The difference plots are presented in green).

unreacted terminal amine appeared in the ${ }^{15} \mathrm{~N}$ CP-MAS NMR spectrum of ${ }^{15} \mathrm{~N}$ enriched COF-1 with the liquid $15 \mathrm{~N}$ NMR spectrum of the ${ }^{15} \mathrm{~N}$ enriched imine model compound as a reference (Fig. S3) [40,50].

The PXRD pattern of QH-COF-1 presents excellent crystallinity with three diffraction peaks at $2.42^{\circ}, 4.16^{\circ}$, and $4.84^{\circ}$, assigned to (100), (110), and (200) reflections, respectively (Fig. 1d). Both the eclipsed and staggered models of QH-COF-1 were constructed using a Material Studio software (Fig. S4). The simulation of the PXRD patterns showed that the structure of QH-COF-1 was consistent with the eclipsed model. Pawley refinement afforded optimize parameters of $a=b=43.751 \AA$, $c$ $=4.334 \AA$ (Table S1), which provided good agreement factors $\left(R_{\mathrm{wp}}=4.25 \%, R_{\mathrm{p}}=2.90 \%\right)$. The cell parameter $(c)$ value (usually expresses the distance between layer to layer) was significantly larger than the value of the traditional imine COF. This is possibly due to the conformational flexibility of the secondary amine linkages, which weakens the $\pi-\pi$ interaction between the adjacent COF layers. Similar to QH-COF-1, the PXRD patterns of COF-1 also presented high crystallinity with three diffraction peaks at $2.46^{\circ}, 4.26^{\circ}$, and $4.91^{\circ}$, assigned to the (100), (110), and (200) reflections, respectively (Fig. S5). COF-1 was also consistent with the eclipsed model, and Pawley refinement afforded the optimize parameters of $a=b=44.493 \AA$, $c=3.900$ $\AA$ with good agreement factors $\left(R_{\mathrm{wp}}=5.95 \%, R_{\mathrm{p}}=4.58 \%\right)(\mathrm{Ta}-$ ble S2).

The $\mathrm{N}_{2}$ sorption isotherms of QH-COF-1 and COF-1 measured at $-196{ }^{\circ} \mathrm{C}$ after activation in vacuo are of type IV, which is typical for mesoporous materials (Fig. S6). The Brunauer-Emmett-Teller (BET) surface areas of QH-COF-1 and COF-1 were calculated to be 674 and $1308 \mathrm{~m}^{2} \mathrm{~g}^{-1}$, respectively (Table S3). QH-COF-1 and COF-1 have total pore volumes of 0.43 and $0.76 \mathrm{~cm}^{3} \mathrm{~g}-1$. respectively. The nonlocal density-functional theory gave rise to a narrow pore size distribution with average pore sizes of 2.2 and $2.7 \mathrm{~nm}$ for QH-COF-1 and COF-1, respectively. Scanning electron microscopic (SEM) images revealed that all the COFs are composed of irregularly shaped particles with a particle size of $\sim 1 \mu \mathrm{m}$ (Fig. S7).

The results of all the above characterizations confirmed that QH-COF-1 with high crystallinity was successfully formed via one-pot cascade reactions.

\subsection{Ultrastability of QH-COF-1}

In general, stability is critical for COFs; therefore, the thermal and chemical stabilities of QH-COF-1 were investigated and compared with those of COF-1. The thermogravimetric analysis (TGA) showed that both QH-COF-1 and COF-1 are thermally stable up to $400{ }^{\circ} \mathrm{C}$ in air, suggesting the high thermal stability of both COFs (Fig. S8). To our delight, the PXRD patterns, $\mathrm{N}_{2}$ 

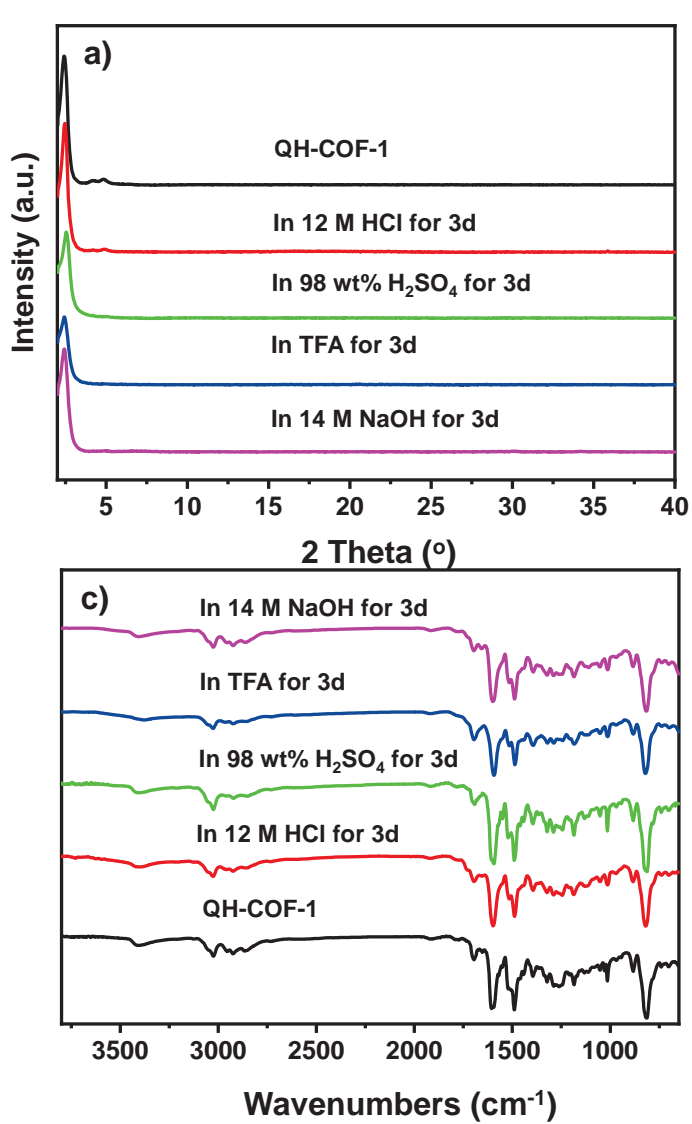
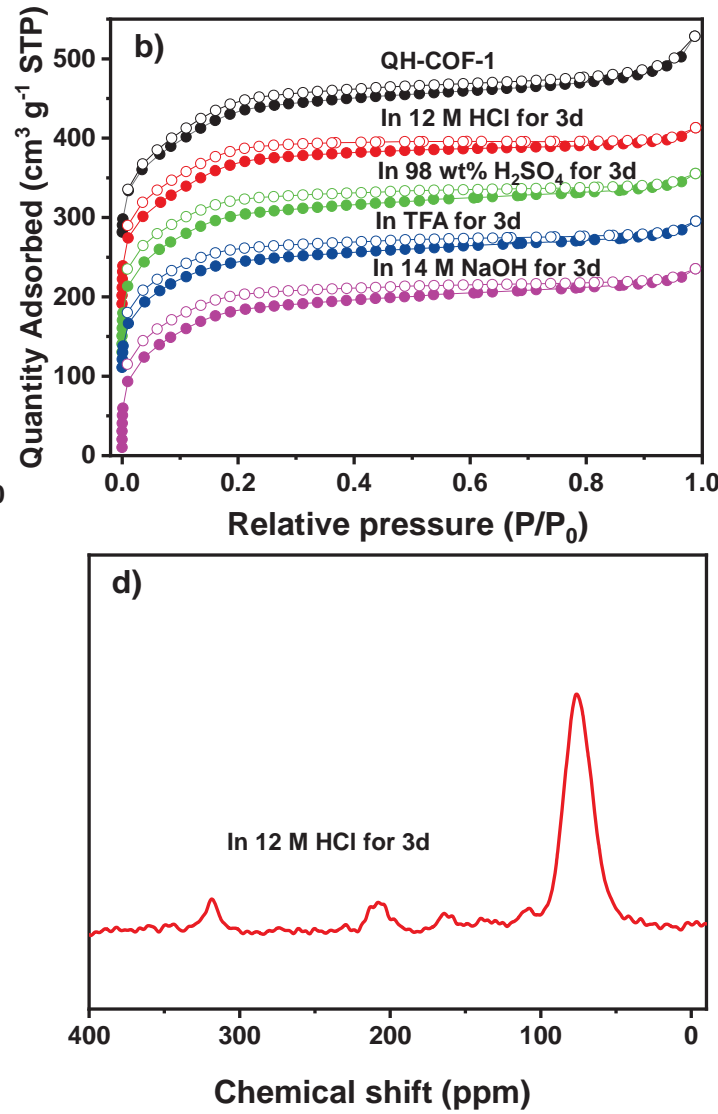

Fig. 2. (a) PXRD patterns, (b) $\mathrm{N}_{2}$ isotherms (the isotherms have been shifted vertically), and (c) FT-IR spectra of QH-COF-1 measured after treatment

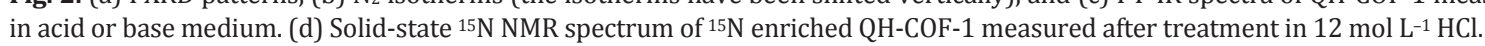

sorption isotherms, FT-IR spectra, and SEM images of QH-COF-1 after treatment in TFA, $12 \mathrm{~mol} \mathrm{~L}^{-1} \mathrm{HCl}, 14 \mathrm{~mol} \mathrm{~L}^{-1}$ $\mathrm{NaOH}$, and even concentrated $\mathrm{H}_{2} \mathrm{SO}_{4}$ (98\%) remained almost unchanged, indicating that QH-COF-1 could tolerate strong acid and base conditions (Figs. 2, S9). Furthermore, the ${ }^{15} \mathrm{~N}$ NMR spectrum of ${ }^{15} \mathrm{~N}$ enriched QH-COF-1 after treatment in $12 \mathrm{~mol}$ $\mathrm{L}^{-1} \mathrm{HCl}$ for 3 days was almost identical to that of the fresh one, which further confirmed the excellent chemical stability of QH-COF-1. The weak signal at $\sim 210 \mathrm{ppm}$ was possibly derived from the protonated nitrogen of the secondary amine. On the contrary, the imine-linked COF (COF-1) was destroyed almost completely in acid or base solutions under similar conditions, indicating that the imine-linked structure was not stable under harsh acid or base conditions. The above results confirmed the ultrastability of QH-COF-1 under harsh conditions. As far as we know, QH-COF-1 is one of the most stable COFs ever reported.

\subsection{Universality of the one-pot cascade reactions for the syn- thesis of ultrastable COFs}

Theoretically, most of the monomers employed for the synthesis of imine-linked COFs could be used for the construction of tetrahydroquinoline-linked COFs under suitable conditions. To explore the universality of this one-pot cascade method for the construction of tetrahydroquino- line-linked COFs, 1,3,5-tris(p-formylphenyl)benzene and 1,3,5-tris(4-aminophenyl)benzene were used as monomers for the synthesis of QH-COF-2 in a similar way to that of QH-COF-1 (Scheme 1). QH-COF-2 exhibits similar a PXRD pattern to that of QH-COF-1 with three diffraction peaks at $4.12^{\circ}, 7.02^{\circ}, 8.20^{\circ}$, assigned to the (100), (110), and (200) reflections, respectively (Fig. 1e). The simulation results showed that QH-COF-2 was consistent with the eclipsed model, and the Pawley refinement afforded optimize parameters of $a=b=26.380 \AA, c=5.484 \AA$ with good agreement factors $\left(R_{\mathrm{wp}}=5.13 \%, R_{\mathrm{p}}=3.95 \%\right)$ (Table S4). The FT-IR (-NH-, $\left.3405 \mathrm{~cm}^{-1} ;-\mathrm{OCH}_{2} \mathrm{CH}_{3}, 2870-2960 \mathrm{~cm}^{-1}\right)$, solid-state ${ }^{13} \mathrm{C}$ CP-MAS NMR (alkyl and alkoxy, 13-68 ppm), and solid-state ${ }^{15} \mathrm{~N}$ CP-MAS NMR (-15NH-, 75 ppm) spectra of QH-COF-2 confirmed the successful formation of a tetrahydroquinoline linkage in QH-COF-2 (Fig. 1). The weak signals at 307 and $200 \mathrm{ppm}$ are assigned to the nitrogen of quinoline and the nitrogen coordinated with a metal salt, respectively. Similar to QH-COF-1, QH-COF-2 was also chemically stable in TFA, $12 \mathrm{~mol}$ $\mathrm{L}^{-1} \mathrm{HCl}, 14 \mathrm{~mol} \mathrm{~L}-1 \mathrm{NaOH}$, and concentrated $\mathrm{H}_{2} \mathrm{SO}_{4}$ (98\%) as evidenced by the PXRD results (Fig. S10). The successful formation of QH-COF-2 suggests that the one-pot cascade condensation and cycloaddition reaction is a versatile method for the synthesis of ultrastable COFs with tetrahydroquinoline linkage. 

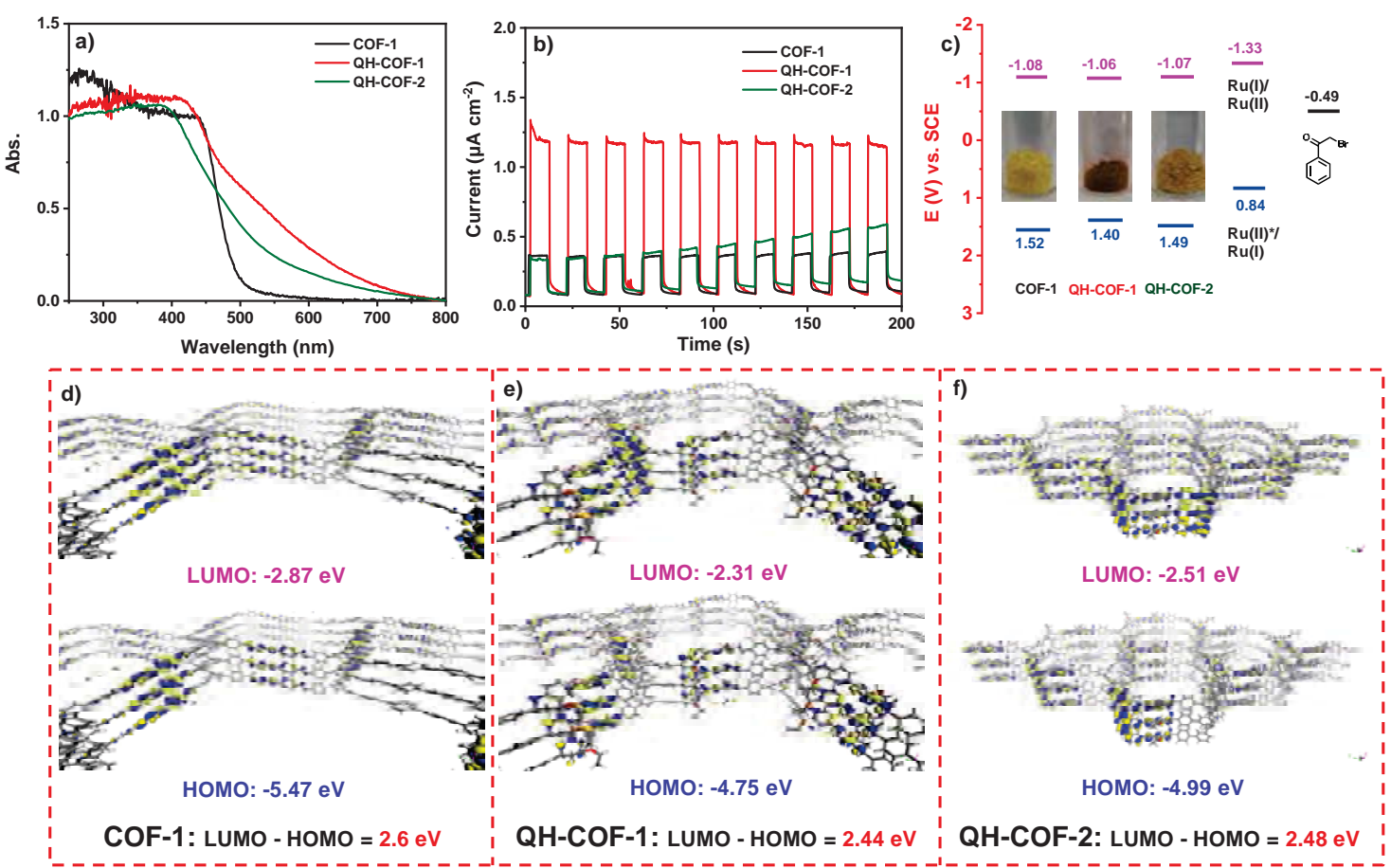

Fig. 3. (a) UV-vis spectra, (b) transient photocurrent responses under visible-light irradiation, (c) CB and VB position (vs. SCE, referenced with molecular photocatalyst $\left[\mathrm{Ru}(\mathrm{bpy})_{3}\right]^{2+}$ and the redox potential of 2-bromoacetophenone) [6,53], and (d-f) pictorial representation of HOMO and LUMO orbitals and their energy levels of QH-COF-1, COF-1, and QH-COF-2.

\subsection{Asymmetric photocatalysis}

Diffuse reflectance ultraviolet-visible (UV-vis) spectroscopy showed that all the COFs could efficiently absorb visible light (Fig. 3a). In comparison with the COF-1 spectrum, the QH-COF-1 spectrum exhibited a noticeable red-shift of the absorption edge from $\sim 480 \mathrm{~nm}$ to $>560 \mathrm{~nm}$. The spectrum of QH-COF-2 showed an absorption edge extending to more than $550 \mathrm{~nm}$. The optical band gaps of QH-COF-1, QH-COF-2, and COF-1 were estimated to be 2.46, 2.56, and $2.60 \mathrm{eV}$ from Kubelka-Munk plots, respectively (Fig. S11). The corresponding THQ and imine model compounds only absorb UV light and exhibit considerably broad band gaps (Fig. S12). The band gaps of QH-COF-1, QH-COF-2, and COF-1 were further calculated using the self-consistent-charge density-functional tight-binding (SCC-DFTB) method based on the DFTB + Material Studio Software (Fig. 3; for details, see SI). The calculated results showed that the band gaps of QH-COF-1 and COF-1 are almost similar to the experimental data. For QH-COF-2, the calculated band gap is relatively narrower than the experimental data. This is possibly due to the fact that precise modeling is difficult for QH-COF-2 with moderate crystallinity. All the COFs show a noticeable photocurrent under visible-light irradiation, suggesting the efficiency of the separation of the photogenerated charges in COFs (Fig. 3b). Electrochemical impedance spectroscopy (EIS) was exploited to investigate the electrical conductivity of the COFs (Fig. S13). The semicircular radius on the EIS Nyquist plot of QH-COF-1 was smaller than those of QH-COF-2 and COF-1, indicating that the charge transport efficiency in QH-COF-1 is higher. QH-COF-1 afforded much higher photocurrent under visible-light irradiation than those of QH-COF-2 and COF-1, which could be attributed to the narrow band gap and enhanced charge transportation efficiency. The conduction band (CB) levels of QH-COF-1, QH-COF-2, and COF-1 were respectively located at $-1.06,-1.07$, and -1.08 eV vs. SCE, respectively, as determined by cyclic voltammetry measurement (Fig. S14). The estimated band gaps, band structures, and energy levels of QH-COF-1, QH-COF-2, and COF-1 are summarized in Fig. 3c. The above results suggest that the band gap could be narrowed by the formation of a tetrahydroquinoline linkage and that the band edge could be finely tuned by varying the chemical composition of the monomers.

The merging of photo-redox catalysis with asymmetric catalysis has attracted great research interest over the past decades [51-60]. One of the milestone work focused on combining photocatalysis with asymmetric organocatalysis was reported by MacMillan and co-workers [51]. To date, most asymmetric photocatalysis processes employ $\left[\mathrm{Ru}(\mathrm{bpy})_{3}\right]^{2+}$ or organic dyes as photocatalysts. The narrow light absorption range, difficult recyclability, photobleaching, and low anti-photo corrosion ability are the main shortcomings for the molecular photosensitizer. The potentials of visible-light responsive QH-COF-1, QH-COF-2, and COF-1 materials in the field of photocatalysis were investigated in asymmetric MacMillan reactions considering their suitable band structures, based on the previous reports using $(2 R, 5 S)$-2-tert-butyl-3,5-dimethylimidazolidin4-one triflate as a chiral organocatalyst (Table 1).

QH-COF-1 could efficiently catalyze the MacMillan reaction to afford the corresponding product with a $75 \%$ isolation yield 
Table 1

The catalytic performances of different types of photocatalysts in the asymmetric $\alpha$-alkylation of aldehydes.

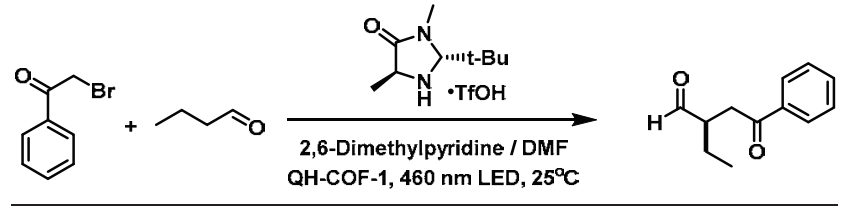

\begin{tabular}{|c|c|c|}
\hline Photocatalyst & Yield a (\%) & ee $^{\mathrm{b}}(\%)$ \\
\hline None & N.D. & - \\
\hline QH-COF- $1^{\mathrm{d}}$ & N.D. & 一 \\
\hline THQ & N.D. & - \\
\hline QH-COF-1 & 75 & 91 \\
\hline COF-1 & 30 & 84 \\
\hline QH-COF-2 & 60 & 91 \\
\hline$\left[\mathrm{Ru}(\mathrm{bpy})_{3}\right] \mathrm{Cl}_{2} \cdot 6 \mathrm{H}_{2} \mathrm{O}$ e & 80 & 91 \\
\hline $\mathrm{BiVO}_{4}$ & 20 & 91 \\
\hline $\mathrm{WO}_{3}$ & 18 & 88 \\
\hline $\mathrm{TiO}_{2}(\mathrm{P} 25)$ & 27 & 91 \\
\hline QH-COF-1 (TEMPO) ${ }^{\mathrm{f}}$ & $<3$ & 一 \\
\hline QH-COF-1 (DIPEA)g & $<3$ & 一 \\
\hline
\end{tabular}

Reaction conditions: 2-bromoacetophenone (0.809 $\mathrm{mol})$ $n$-butyraldehyde (1.62 mmol), 2,6-dimethlpyridine (1.62 mmol), $(2 R, 5 S)$-2-tert-butyl-3,5-dimethylimidazolidin-4-one triflate salt $(0.162$ mmol), photocatalyst (30 mg), anhydrous DMF ( $2 \mathrm{~mL}$ ), irradiation with

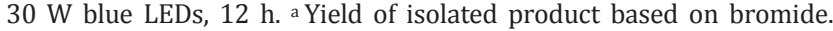
b Determined by ${ }^{1} \mathrm{H}$ NMR analysis of the diastereometric acetals obtained by derivatization with $(2 S, 4 S)$-2,4-pentanediol. ${ }^{\mathrm{c}} \mathrm{N} . \mathrm{D} . \mathrm{=}$ not detected. ${ }^{\mathrm{d}}$ Light off. e $\left[\mathrm{Ru}(\mathrm{bpy})_{3}\right] \mathrm{Cl}_{2} \cdot 6 \mathrm{H}_{2} \mathrm{O}(8.09 \mu \mathrm{mol}) .{ }^{\mathrm{f}}$ TEMPO (1.62 mmol). g DIPEA (1.62 mmol).

and $91 \%$ ee. Under similar conditions, $\left[\mathrm{Ru}(\mathrm{bpy})_{3}\right]^{2+}$ afforded an $80 \%$ yield with $91 \%$ ee. The almost comparable catalytic performances of QH-COF-1 and [Ru(bpy) $]^{2+}$ suggested that QH-COF-1 is an efficient photocatalyst for the asymmetric MacMillan reaction. QH-COF-2 afforded less yield than QH-COF-1 (60\% versus 75\%), possibly due to its wider band gap and reduced charge separation efficiency. COF-1 afforded a much lower yield (30\% versus $75 \%$ ) and ee value (84\% versus 91\%) than QH-COF-1, possibly due to its low stability under photocatalytic conditions. After one cycle, less than $20 \%$ of the initial COF-1 amount could be recovered and most COF-1 decomposed during the photocatalytic process. Due to its ultra- high stability, QH-COF-1 could be recovered without notable weight loss after the photocatalytic reaction, further confirming the superiority of tetrahydroquinoline-linked COFs in photocatalysis.

Inorganic photocatalysts, $\mathrm{BiVO}_{4}, \mathrm{WO}_{3}$, and $\mathrm{TiO}_{2}$, could also catalyze the asymmetric MacMillan reaction under similar conditions. The ee value over $\mathrm{BiVO}_{4}$ and $\mathrm{TiO}_{2}$ could reach up to $91 \%$, while $\mathrm{WO}_{3}$ afforded a slightly lower ee value of $88 \%$. All the inorganic photocatalysts screened here afforded much lower product yields than QH-COF-1. The photogenerated electrons and holes are both involved in the asymmetric MacMillan reaction based on the reaction mechanism (discussed later). An efficient photocatalyst should be able to absorb visible light and possess suitable redox properties of electrons and holes. The visible-light responsive $\mathrm{BiVO}_{4}$ and $\mathrm{WO}_{3}$ have relatively low electron reducing power [61], while $\mathrm{TiO}_{2}$ with stronger redox properties has a wide band gap [62]. Consequently, they are not efficient photocatalysts for the asymmetric MacMillan reaction. As far as we know, QH-COF-1 is the most active organic semiconductor for the asymmetric MacMillan reaction. The superiority of QH-COF-1 for the organic asymmetric photocatalysis is mainly related to its narrow band gap and suitable band edge.

To investigate the reaction mechanism of the asymmetric photocatalysis, we performed a series of controlled experiments. In the absence of photocatalysts or without light, no product was detected, confirming that the asymmetric MacMillan reaction indeed involves the photocatalytic process. With THQ as the photocatalyst, no product was detected under similar conditions, suggesting that it was not the tetrahydroquinoline fragments but QH-COFs that acted as the photocatalyst. When the reaction was performed in the absence of a chiral secondary amine, no product was obtained. This implies the QH-COFs cannot catalyze the condensation of a secondary amine with an aldehyde. In the presence of 2 equiv. of TEMPO (radical scavenger) or DIPEA (hole scavenger), the yield of isolated chiral products decreased to less than $3 \%$, suggesting that radical species [63] and oxidative holes both participated in the photocatalytic process. Further, the radical species produced by 2-bromoacetophenone were captured and separated in the

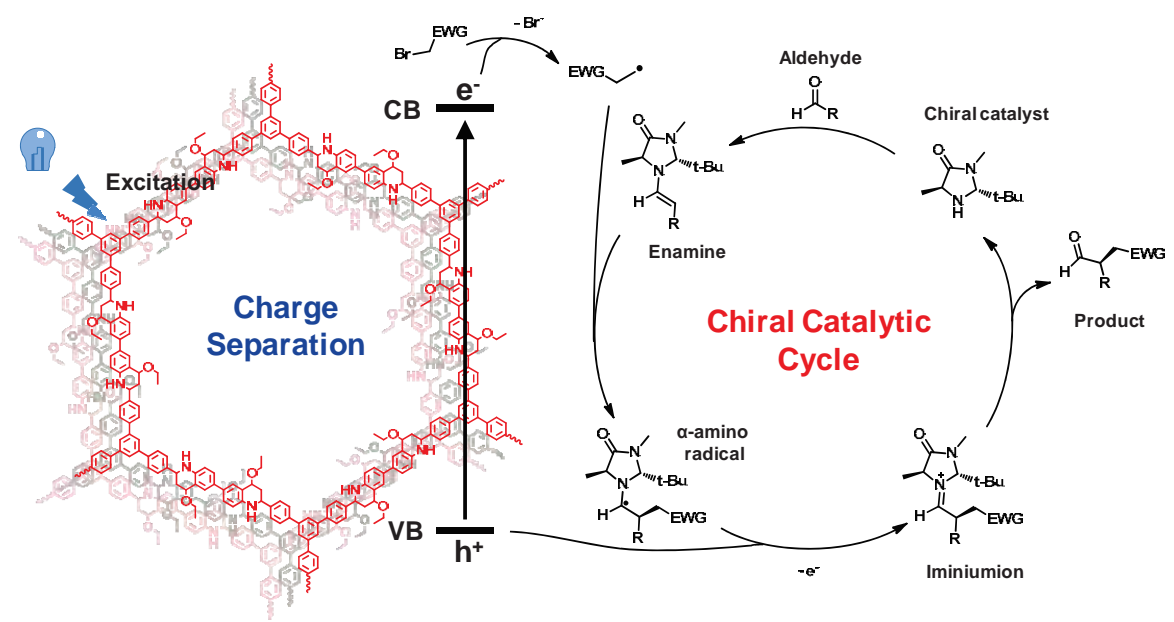

Scheme 2. Proposed mechanism for the photocatalytic asymmetric $\alpha$-alkylation of aldehydes in the presence of QH-COF-1. 


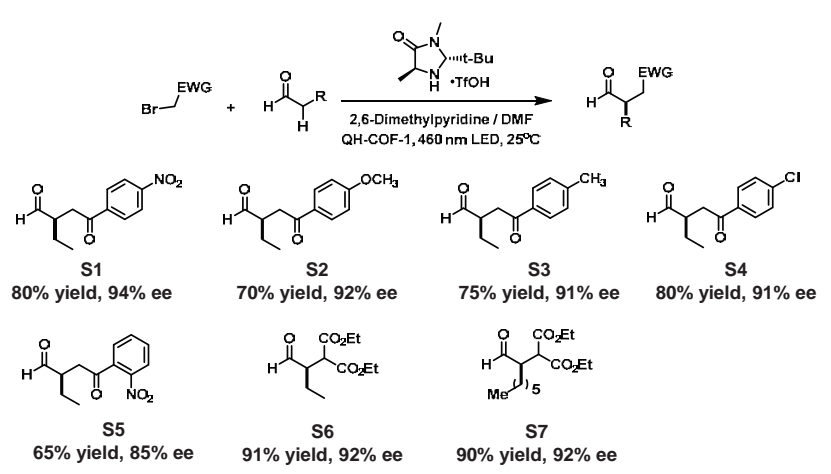

Fig. 4. The substrate scope of asymmetric photocatalysis over QH-COF-1 (S1-S5: 20 h, S6-S7: 6 h).

presence of 1 equiv. of TEMPO and 2 equiv. DIPEA (for details, see SI). The above-controlled experiments indicated that the QH-COF acted as an electron and hole provider. Based on the above results, the schematic diagram of the photocatalytic reaction process is outlined in Scheme 2. Under light irradiation, the photogenerated electrons transferred from the $\mathrm{CB}$ of QH-COF-1 to $\alpha$-bromocarbonyl substrate to form an electron-deficient alkyl radical. In the following step, an $\alpha$-amino radical was produced by the addition of the electron-deficient alkyl radical to the enamine formed by the condensation of the chiral secondary amine with the aldehyde. The hole in the VB of QH-COF-1 would remove a single electron from a sacrificial quantity of $\alpha$-amino radical to form the iminiumion that decomposed into the catalyst and product to complete the cycle [51,53].

As shown in Fig. 4, a series of 2-bromoacetophenone derivatives with both electron-withdrawing and electron-donation substituents and diethyl bromomalonate could be smoothly reacted with aldehyde for the production of corresponding alkylation products in the presence of QH-COF-1 with high isolated yield (65\%-91\%) and ee value (85\%-94\%). The wide substrate scope of the asymmetric photocatalysis validates the generality of QH-COFs as a privileged photocatalyst.

The recycling stability of QH-COF-1 was investigated in the production of S6 (Fig. 5). Even after five cycles, QH-COF-1 still afforded a high yield (87\%) and high ee (92\%). The recovered
QH-COF-1 produced an almost identical PXRD pattern, FT-IR spectrum, and SEM image compared with those of the fresh one, showing the structural and morphological stability under light irradiation (Figs. 5, S9, and S15). This suggests that QH-COFs have ultrahigh photostability, which makes them superior to most reported COFs.

\section{Conclusions}

In summary, we successfully developed an efficient and general method to build QH-COFs as robust photocatalysts via the one-pot Povarov reaction. QH-COFs could endure strong acidic/basic conditions and light irradiation, which is attributed to the irreversible tetrahydroquinoline linkage. The formation of tetrahydroquinoline linkage could effectively narrow the band gap of QH-COFs to widen the absorption spectrum. The QH-COFs exhibited high activity, enantioselectivity, and excellent recyclability in the photocatalytic asymmetric MacMillan reaction by merging with a chiral secondary amine. Theoretically, all imine-linked COFs that have been reported could be converted into stable tetrahydroquinoline-linked structures under optimized conditions, considering that the functional groups for further transformation are no longer required to be attached to the monomers. Our work would shed light on the designable synthesis of robust COFs with novel irreversible linkages. This research also demonstrates the promising applications of ultrastable COFs with designable band structures, porosity, and lipophilicity in the field of visible-light-driven APOS.

\section{Acknowledgments}

We are grateful to Prof. X. Feng and Mr. P. Shao for the support on the structural modeling of COFs. H. Li thanks Ms. X. Tao for helpful discussions.

\section{References}

[1] C. R. J. Stephenson, T. P. Yoon, D. W. C. MacMillan, Visble Light Photocatalysis in Organic Chemistry, Wiley, Weinheim, 2018.

[2] Q. M. Kainz, C. D. Matier, A. Bartoszewicz, S. L. Zultanski, J. C. Peters, G. C. Fu, Science, 2016, 351, 681-684.
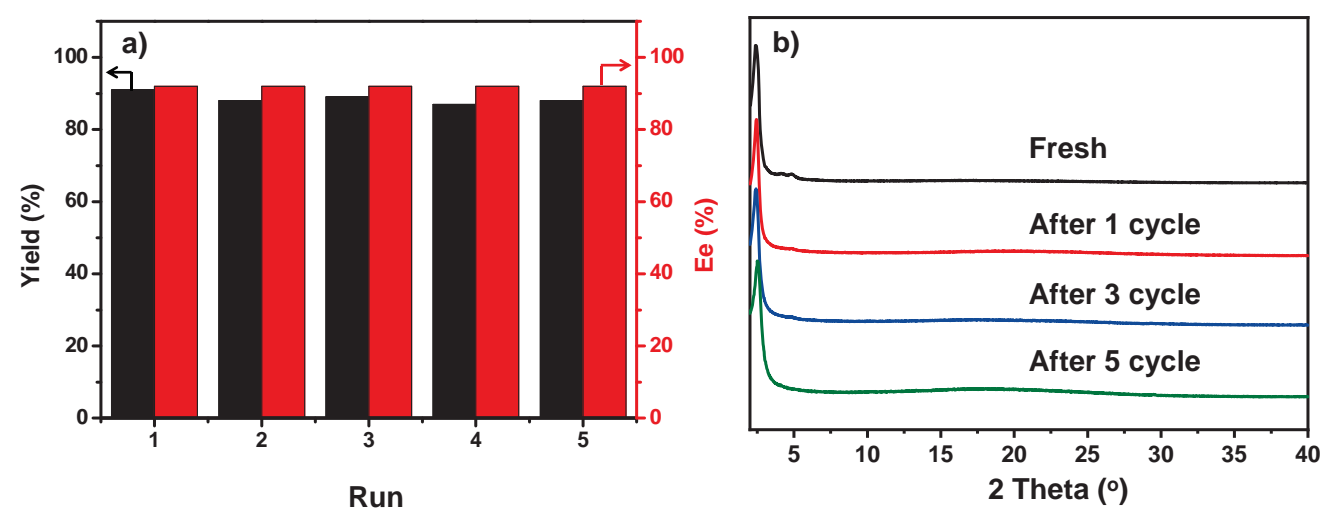

Fig. 5. (a) The recycling stability of QH-COF-1 in the asymmetric MacMillan reaction with $n$-butyraldehyde and diethyl bromomalonate as model substrates; (b) PXRD patterns of the recovered QH-COF-1. 


\section{Graphical Abstract}

Chin. J. Catal., 2020, 41: 1288-1297 doi: 10.1016/S1872-2067(20)63572-0

Asymmetric photocatalysis over robust covalent organic frameworks with tetrahydroquinoline linkage

Chunzhi Li, Yinhua Ma, Haoran Liu, Lin Tao, Yiqi Ren, Xuelian Chen, He Li*, Qihua Yang *

Dalian Institute of Chemical Physics, Chinese Academy of Sciences; University of Chinese Academy of Sciences

The synthesis of robust COFs with an irreversible tetrahydroquinoline linkage was established, and the potential application of QH-COFs in the photocatalytic asymmetric MacMillan reaction was demonstrated for the first time by merging with the chiral secondary amine.

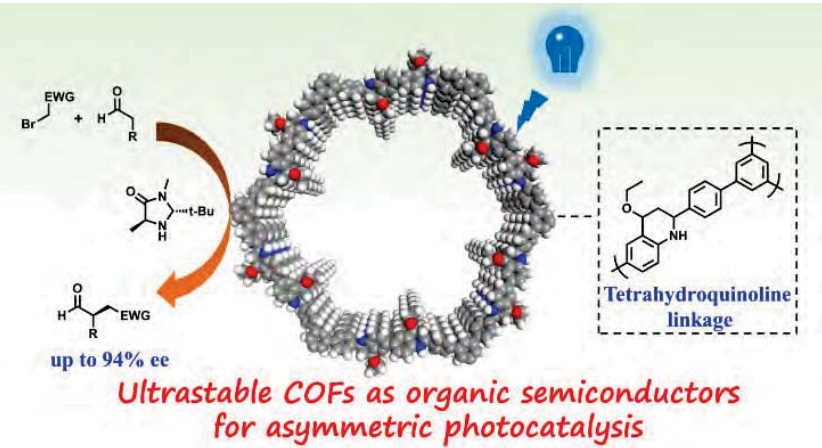

Chem. Soc., 2019, 141, 7615-7621.

[23] M. Lu, Q. Li, J. Liu, F.-M. Zhang, L. Zhang, J.-L. Wang, Z.-H. Kang, Y.-Q. Lan, Appl. Catal. B, 2019, 254, 624-633.

[24] Y. Fu, X. Zhu, L. Huang, X. Zhang, F. Zhang, W. Zhu, Appl. Catal. B, 2018, 239, 46-51.

[25] M. Lu, J. Liu, Q. Li, M. Zhang, M. Liu, J.-L. Wang, D.-Q. Yuan, Y.-Q. Lan, Angew. Chem. Int. Ed., 2019, 58, 12392-12397.

[26] W. Liu, Q. Su, P. Ju, B. Guo, H. Zhou, G. Li, Q. Wu, ChemSusChem, 2017, 10, 664-669.

[27] Y. Zhi, Z. Li, X. Feng, H. Xia, Y. Zhang, Z. Shi, Y. Mu, X. Liu, J. Mater. Chem. A, 2017, 5, 22933-22938.

[28] S. Liu, W. Pan, S. Wu, X. Bu, S. Xin, J. Yu, H. Xu, X. Yang, Green Chem., 2019, 21, 2905-2910.

[29] M. Bhadra, S. Kandambeth, M. K. Sahoo, M. Addicoat, E. Balaraman, R. Banerjee, J. Am. Chem. Soc., 2019, 141, 6152-6156.

[30] Z. Li, Y. Zhi, P. Shao, H. Xia, G. Li, X. Feng, X. Chen, Z. Shi, X. Liu, Appl. Catal. B, 2019, 245, 334-342.

[31] R. Chen, J.-L. Shi, Y. Ma, G. Lin, X. Lang, C. Wang, Angew. Chem. Int. Ed., 2019, 58, 6430-6434.

[32] P.-F. Wei, M.-Z. Qi, Z.-P. Wang, S.-Y. Ding, W. Yu, Q. Liu, L.-K. Wang, H.-Z. Wang, W.-K. An, W. Wang, J. Am. Chem. Soc., 2018, 140, 4623-4631.

[33] P. J. Waller, S. J. Lyle, T. M. O. Popp, C. S. Diercks, J. A. Reimer, O. M. Yaghi, J. Am. Chem. Soc., 2016, 138, 15519-15522.

[34] X. Li, C. Zhang, S. Cai, X. Lei, V. Altoe, F. Hong, J. J. Urban, J. Ciston, E. M. Chan, Y. Liu, Nat. Commun., 2018, 9, 2998.

[35] B. Zhang, M. Wei, H. Mao, X. Pei, S. A. Alshmimri, J. A. Reimer, O. M. Yaghi, J. Am. Chem. Soc., 2018, 140, 12715-12719.

[36] H. Lyu, C. S. Diercks, C. Zhu, O. M. Yaghi, J. Am. Chem. Soc., 2019, 141, 6848-6852.

[37] X. Guan, H. Li, Y. Ma, M. Xue, Q. Fang, Y. Yan, V. Valtchev, S. Qiu, Nat. Chem., 2019, 11, 587-594.

[38] D. A. Pyles, W. H. Coldren, G. M. Eder, C. M. Hadad, P. L. McGier, Chem. Sci., 2018, 9, 6417-6423.

[39] H. Liu, J. Chu, Z. Yin, X. Cai, L. Zhuang, H. Deng, Chem, 2018, 4, 1696-1709.

[40] S. J. Lyle, T. M. O. Popp, P. J. Waller, X. Pei, J. A. Reimer, O. M. Yaghi, J. Am. Chem. Soc., 2019, 141, 11253-11258.

[41] F. Haase, E. Troschke, G. Savasci, T. Banerjee, V. Duppel, S. Dörfler, M. M.J. Grundei, A. M. Burow, C. Ochsenfeld, S. Kaskel, B. V. Lotsch, Nat. Commun., 2018, 9, 2600.

[42] S. Kandambeth, A. Mallick, B. Lukose, M. V. Mane, T. Heine, R.

[22] W. Zhong, R. Sa, L. Li, Y. He, L. Li, J. Bi, Z. Zhuang, Y. Yu, Z. Zou, J. Am. 
Banejee, J. Am. Chem. Soc., 2012, 134, 19524-19527.

[43] V. V. Kouznetsov, Tetrahedron, 2009, 65, 2721-2750.

[44] S. Kobayashi, H. Ishitani, S. Nagayama, Synthesis, 1995, 9, 1195-1202.

[45] H. Laurent-Robert, B. Garrigues, J. Dubac, Synlett, 2000, 8, 1160-1162.

[46] M. Matsumoto, R. R. Dasari, W. Ji, C. H. Feriante, T. C. Parker, S. R. Marder, W. R. Dichtel, J. Am. Chem. Soc., 2017, 139, 4999-5002.

[47] H. Li, X. Feng, P. Shao, J. Chen, C. Li, S. Jayakumar, Q. Yang, J. Mater. Chem. A, 2019, 7, 5482-5492.

[48] L.-K. Wang, J.-J. Zhou, Y.-B. Lan, S.-Y. Ding, W. Yu, W. Wang, Angew. Chem. Int. Ed., 2019, 58, 9443-9447.

[49] P. S. Pregosin, E. W. Randall, A. I. White, J. Chem. Soc. Perkin Trans., 1972, 2, 1-4.

[50] K. Gottschling, L. Stegbauer, G. Savasci, N. A. Prisco, Z. J. Berkson, C. Ochsenfeld, B. F. Chmelka, B. V. Lotsch, Chem. Mater., 2019, 31, 1946-1955.

[51] D. A. Nicewicz, D. W. C. MacMillan, Science, 2008, 322, 77-80.

[52] D. A. Nagib, M. E. Scott, D. W. C. MacMillan, J. Am. Chem. Soc., 2009, 131, 10875-10877.

[53] M. Neumann, S. Füldner, B. König, K. Zeitler, Angew. Chem. Int. Ed.,
2011, 50, 951-954.

[54] H.-W. Shih, M. N. Vander Wal, R. L. Grange, D. W. C. MacMillan, J. Am. Chem. Soc., 2010, 132, 13600-13603.

[55] P. Wu, C. He, J. Wang, X. Peng, X. Li, Y. An, C. Duan, J. Am. Chem. Soc., 2012, 134, 14991-14999.

[56] H. Huo, X. Shen, C. Wang, L. Zhang, P. Röse, L.-A. Chen, K. Harms, M. Marsch, G. Hilt, E. Meggers, Nature, 2014, 515, 100-103.

[57] R. Brimioulle, D. Lenhart, M. M. Maturi, T. Bach, Angew. Chem. Int. Ed., 2015, 54, 3872-3890.

[58] Y. Zhang, Y. Zhu, W. Zhou, X. Qiu, Z. Tang, Part. Part. Syst. Charact., 2018, 35, 1700280.

[59] Y. Zhang, J. Guo, L. Shi, Y. Zhu, K. Hou, Y. Zheng, Z. Tang, Sci. Adv., 2017, 3, e1701162.

[60] E. Arceo, I. D. Jurberg, A. Álvarez-Fernández, P. Melchiorre, Nat. Chem., 2013, 5, 750-756.

[61] Z. Qin, W. Fang, J. Liu, Z. Wei, Z. Jiang, W. Shangguan, Chin. J. Catal., 2018, 39, 472-478.

[62] Y. Xiao, X. Sun, L. Li, J. Chen, S. Zhao, C. Jiang, L. Yang, L. Cheng, S. Cao, Chin. J. Catal., 2019, 40, 765-775.

[63] N. S. Dange, A. H. Jatoi, F. Robert, Y. Landais, Org. Lett., 2017, 19, 3652-3655.

\title{
新型超稳定四氢喹啉连接的共价有机骨架材料的制备及其不对称光催化性能

\author{
李纯志 ${ }^{\mathrm{a}, \mathrm{b}}$, 马银华 ${ }^{\mathrm{b}, \mathrm{c}}$, 刘浩然 ${ }^{\mathrm{a}}$, 陶 琳 $^{\mathrm{a}, \mathrm{b}}$, 任亦起 ${ }^{\mathrm{a}, \mathrm{b}}$, 陈雪莲 ${ }^{\mathrm{a}}$, 李 贺 ${ }^{\mathrm{a}}{ }^{*}$, 杨启华 ${ }^{\mathrm{a}, \#}$ \\ a中国科学院大连化学物理研究所催化基础国家重点实验室, 辽宁大连116023 \\ b中国科学院大学, 北京100049 \\ c中国科学院大连化学物理研究所分子反应动力学国家重点实验室, 辽宁大连116023
}

\begin{abstract}
摘要: 不对称光催化有机合成是一种可持续的、环境友好的以太阳光为能源生产光学活性化学品的方法. 绝大多数不对称 光催化有机合成体系是由有机染料或无机半导体作为捕光材料与手性催化剂耦合构成. 然而通常面临有机染料吸收谱带 窄、光腐蚀严重, 以及无机半导体材料的能带结构和带隙难以调控等问题. 直到目前, 仍然缺乏具有可调节带隙结构和高 循环稳定性的半导体材料. 最近, 一类通过共价键连接形成、具有晶态有序结构的共价有机骨架材料(COFs)被报道用于光 催化有机合成. 但多数COFs材料均由可逆的化学键 (如B-O-B键、 $-\mathrm{C}=\mathrm{N}$ 键等)构成, 其化学稳定性和光稳定性有待提升. 目 前已报道的一些稳定COFs均基于特殊的单体结构或通过后修饰策略制备, 其合成路线过长并需要对单体进行额外的修饰. 本文中, 我们发展了一种具有普适性的通过不可逆四氢喹啉连接的COFs材料的制备方法, 并考察了该材料在不对称光催 化反应中的活性和稳定性.

我们以1,3,5-三(4’-醛基苯基)苯、1,3,5-三(4'-氨基苯基)苯(或联苯胺)和乙烯基乙醚为原料, 以三氟甲磺酸䥻和三氟甲磺 酸镱为催化剂, 通过一锅法波瓦罗夫反应制备了两种以不可逆四氢哇啉连接的新型共价有机骨架材料QH-COFs. QH-COFs材料表现出了极高的化学稳定性, 在浓硫酸、浓盐酸、三氟乙酸或氢氧化钠溶液中浸泡三天, 其比表面积和结晶 性均没有发生明显变化. QH-COFs(作为半导体)和手性二级胺(为手性催化剂)在可见光下可高效催化醛的不对称 $\alpha$ 烷基化 反应, ee值高达 $94 \%$. 由于QH-COFs 具有窄的禁带宽度和适合的能带结构, 在相同条件下, QH-COFs的活性明显优于无机半 导体(如二氧化钛、钒酸铋、三氧化铇等). QH-COFs 是迄今为止报道的在可见光下催化醛的不对称 $\alpha$ 烷基化反应活性最高 的半导体材料. 由于四氢喹啉结构的存在, QH-COFs 具有极高的循环稳定性, 在循环五次之后, 活性和ee值没有发生明显 下降, 并且其仍保持高结晶性. 理论上所有可构筑亚胺COFs的单体均可通过该策略制备出稳定四氢喹啉结构的COFs材料, 且无需对单体作任何修饰. 该工作不仅为不对称光催化开辟了一条新途径, 同时也为构筑稳定的COFs材料提供了一种高 效、普适性方法.
\end{abstract}

关键词: 光催化; 共价有机骨架材料; 四氢喹啉; 不对称催化; 超高稳定性

收稿日期: 2019-11-27. 接受日期: 2019-12-23. 出版日期: 2020-08-05.

*通讯联系人. 电话: (0411)82463019; 传真: (0411)84694447; 电子信箱: lihe@dicp.ac.cn

\#通讯联系人. 电话: (0411)84379552; 传真: (0411)84694447; 电子信箱: yangqh@dicp.ac.cn 基金来源：国家自然科学基金(21733009, 21621063); 中国科学院战略性先导科技专项(XDB17020200).

本文的电子版全文由Elsevier出版社在ScienceDirect上出版(http://www.sciencedirect.com/science/journal/18722067). 